\title{
IMPLEMENTASI PROGRAM KAMPUNG KELUARGA BERENCANA (KB) DI KELURAHAN DANGERAKKO KECAMATAN WARA KOTA PALOPO PROVINSI SULAWESI SELATAN
}

\author{
Oleh \\ Zakiah Jamaluddin ${ }^{1}$, \\ Muh Ilham², Udaya Madjid ${ }^{3}$ \\ 1) Institut Pemerintahan Dalam Negeri \\ Program Magister Terapan Studi Pemerintahan Daerah Institut Pemerintahan Dalam Negeri \\ zakiahjamaluddin07@gmail.com \\ ${ }^{2,3)}$ Institut Pemerintahan Dalam Negeri
}

\begin{abstract}
"IMPLEMENTATION OF KAMPUNG KELUARGA BERENCANA (KB) PROGRAM AT DANGERAKKO VILLAGE WARA DISTRICT PALOPO CITY, SOUTH SULAWESI PROVINCE"

The Kampung KB program is a government effort not only to control the population but also
to improve the quality of life through community participation starting from the village area. Palopo as the city in South Sulawesi with the highest growth rate and the third most populous city has launched the program in 8 locations, one of which is in Dangerakko Village, Wara District. This study aims to examine and know clearly the implementation of the Kampung KB Program in Dangerakko Village through a qualitative descriptive approach. Data collection obtained through interviews, documentation, and observation. The informants were determined through snowball sampling with the Head of Dangerakko as the key informant. The data used are primary and secondary data, which are then analyzed through data reduction, presentation of data and drawing conclusions. The results of research in the field show that the implementation of the Kampung KB Program in Dangerakko Village is running well, seen from the fulfillment of indicators of adequate resources as program implementers, the community's own understanding of improving the quality of life which is a shared task not just the government, and community support for the success of the program. Community openness and a high level of participation are the supporting factors for the success of the program. The situation of the Covid-19 pandemic has become an obstacle that has stopped routine training and socialization activities. Efforts made to keep this program running are through coordination with the Health Office, Task Force and related agencies to support the implementation of programs that are adaptive to the pandemic situation.
\end{abstract}

Keywords: implementation, kampung kb, program, welfare

\section{ABSTRAK}

$\mathrm{P}$ rogram Kampung KB merupakan usaha pemerintah bukan hanya dalam pengendalian penduduk namun juga peningkatan kualitas hidup melalui partisipasi masyarakat mulai dari wilayah perkampungan. Kota Palopo sebagai kota di Sulawesi Selatan dengan laju 
pertumbuhan tertinggi dan kota terpadat ketiga mencanangkan program tersebut di delapan lokasi, salah satunya ialah di Kelurahan Dangerakko, Kecamatan Wara. Penelitian ini bertujuan mengkaji dan mengetahui secara jelas implementasi Program Kampung KB di Kelurahan Dangerakko melalui pendekatan deskriptif kualitatif. Pengumpulan data diperoleh melalui wawancara, dokumentasi, dan observasi. Informan ditentukan melalui snowball sampling dengan Lurah Dangerakko sebagai informan kunci. Data yang digunakan merupakan data primer dan sekunder, yang selanjutnya dianalisis melalui reduksi data, penyajian data dan penarikan simpulan. Hasil penelitian di lapangan menunjukkan implementasi Program Kampung KB di Kelurahan Dangerakko berjalan baik dilihat dari terpenuhinya indikator sumber daya yang memadai sebagai pelaksana program, pemahaman masyarakat sendiri atas peningkatan kualitas hidup yang menjadi tugas bersama bukan sekadar pemerintah, dan dukungan masyarakat atas keberhasilan program. Keterbukaan masyarakat dan tingkat partisipasi yang tinggi menjadi faktor pendukung keberhasilan program. Situasi pandemik Covid-19 menjadi hambatan yang menjadikan kegiatan pelatihan dan sosialisasi rutin terhenti. Upaya yang dilakukan agar program ini tetap berjalan adalah melalui koordinasi dengan Dinas Kesehatan, Gugus Tugas dan Lembaga terkait untuk mendukung pelaksanaan program yang adaptif dengan situasi pandemi.

Kata kunci: implementasi, kampung kb, kesejahteraan, program

\section{PENDAHULUAN}

I ndonesia diproyeksikan sebagai salah satu negara dengan jumlah penduduk terbesar di dunia. Proyeksi oleh Pew Research Center penduduk Indonesia pada 2020 sebanyak 274 juta jiwa, di bawah Tiongkok, India, dan Amerika Serikat (Jayani, 2019). Besarnya jumlah penduduk ini menunjukkan peningkatan 291,4\% sejak Tahun 1950 yang saat itu sebanyak 70 juta jiwa.

Tabel 1. Negara dengan jumlah Penduduk Terbesar Tahun 2020

\begin{tabular}{clc}
\hline No. & \multicolumn{1}{c}{ Negara } & $\begin{array}{c}\text { Jumlah Penduduk } \\
\text { (jiwa) }\end{array}$ \\
\hline 1 & Tiongkok & 1,4 miliar \\
2 & India & 1,38 miliar \\
3 & Amerika Serikat & 331 juta \\
4 & Indonesia & 274 juta \\
5 & Pakistan & 221 juta \\
6 & Brasil & 213 juta \\
7 & Nigeria & 206 juta \\
8 & Bangladesh & 165 juta \\
9 & Rusia & 146 juta \\
10 & Meksiko & 129 juta \\
\hline
\end{tabular}

Sumber: Pew Research Center, 2019
Keuntungan yang dapat diperoleh dari momen demografis tersebut adalah tersedianya sumber daya manusia yang dapat memfasilitasi pertumbuhan ekonomi yang mendukung kemajuan negara dalam menyejahterakan masyarakatnya (Remi, 2018). Akan tetapi, pertumbuhan penduduk yang tinggi namun tidak disertai pembangunan fisik dan sumber daya akan menimbulkan berdampak terhadap kualitas hidup masyarakat contohnya meningkatnya kemiskinan (Margareni dkk., 2016: 101-110).

Pengendalian tatanan kependudukan agar tetap terkendali, merata dan berbanding lurus dengan perekonomian masyarakat menjadi awal terbentuknya Program Kependudukan dan Keluarga Berencana yang menekankan kewenangan terhadap Badan Kependudukan dan Keluarga Berencana Nasional (BKKBN). Dalam mencapai target dan sasaran penguatan program dimaksud selama 2015-2019, digagaslah Program Kampung KB.

Program Kampung Keluarga Berencana (KB) dicanangkan pada 2016 oleh Presiden RI (Joko Widodo), Adapun faktor-faktor yang melatarbelakangi lahirnya program ini, yaitu sebagai berikut. 
a. Program KB berjalan stagnasi, jika dibandingkan dengan era Orde Baru;

b. Melalui program ini diharapkan dapat meningkatkan kualitas hidup masyarakat serta pembangunan sektor terkait di tingkat desa atau yang setara demi terwujudnya keluarga kecil berkualitas;

c. Mendorong partisipasi masyarakat dalam merubah sikap, perilaku dan mindset ke arah yang lebih baik melalui pengelolaan, penyelenggaraan dari, oleh dan untuk masyarakat;

d. Mengimplementasikan isi Nawacita dalam agenda prioritas ke-3 dan ke-5 dalam hal pembangunan kualitas hidup masyarakat dari pinggiran melalui perkuatan daerahdaerah dan desa Negara Kesatuan Republik Indonesia (NKRI);

e. Bentuk persiapan dalam menghadapi kondisi bonus demografi yang diprediksi terjadi pada 2010-2030.

Sabilla \& Purnaningsih (2020) dalam penelitiannya menyampaikan bahwa salah satu faktor yang menyebabkan program KB berjalan stagnan adalah anggaran di daerah yang minim akibat program $\mathrm{KB}$ tersebut tidak lagi menjadi prioritas pembangunan, sehingga partisipasi masyarakat dalam ber-KB dan meningkatkan kualitas hidup menjadi minim.

Tujuan dari pembentukan Kampung KB adalah peningkatan kualitas hidup masyarakat perkampungan, lewat program Kependudukan, Keluarga Berencana dan Pembangunan Keluarga (KKBPK). Hasil pelaksanaan Program Kampung KB menurut Arinta (2018) dalam penelitiannya memberikan perubahan nyata dalam kehidupan social masyarakat di Kelurahan Harjosari II Medan, Sumatera Utara. Hasil yang diperoleh adalah adanya peningkatan kualitas Kesehatan, utamanya pada keluarga dengan balita, perubahan kualitas lingkungan dan aspek ekonomi menjadi lebih baik.
Sejalan dengan penelitian Restyani \& Yasa (2019) menunjukkan bahwa efektivitas dari pelaksanaan program Kampung KB memberikan kontribusi penting dalam peningkatan kesejahteraan keluarga miskin di Kota Denpasar. Namun, dalam pelaksanaannya, partisipasi masyarakat dinilai sebagai poin penting dalam keberhasilan pelaksanaan program (Anggraeni dkk., 2020)

Pada pelaksanaannya, BKKBN sebagai leading sector atas program ini bersama lembaga pemerintah terkait sampai dengan tahun 2019 telah terbentuk 10.704 desa yang mencanangkan Program Kampung KB se-wilayah Indonesia. Di Provinsi Sulawesi Selatan sendiri jumlah kampung KB sebanyak 374, sementara di Kota Palopo 8 Desa yang telah dicanangkan dalam Program Kampung KB.

Kota Palopo merupakan kota dengan laju pertumbuhan penduduk tertinggi di antara kabupaten/kota di Provinsi Sulawesi Selatan (Badan Pusat Statistik Sulawesi Selatan, 2020). Meski demikian, untuk kepadatan penduduk Kota Palopo berada di posisi ketiga setelah Kota Makassar dan Kota Parepare.

Salah satu wilayah di Kota Palopo yang menjadi lokasi penerapan Program Kampung KB terletak di Kelurahan Dangerakko, Kecamatan Wara. Kelurahan Dangerakko dipilih karena lokasinya yang berada di daerah aliran sungai (DAS), padat penduduk, dengan tingkat kemiskinan tertinggi. Berdasarkan hal tersebut peneliti melakukan penelitian untuk mengetahui bagaimana implementasi Program Kampung KB di Kelurahan Dangerakko, Kecamatan Wara, Kota Palopo.

\section{METODE PENELITIAN}

Pada penelitian ini menggunakan metode penelitian deskriptif kualitatif dengan lokus penelitian pada Kelurahan Dangerakko 
Kecamatan Wara Kota Palopo. Melalui metode ini diharapkan penelitian dapat dilakukan secara naturalistik, apa adanya, tidak dalam kondisi yang dimanipulasi, dan menekankan pada deskripsi alami (Arikunto, 2019). Pengumpulan data dilakukan melalui wawancara dan dokumentasi. Informan ditentukan menggunakan teknik snowball sampling. Teknik ini diharapkan dapat menemukan dan mengidentifikasi informan yang memberikan informasi secara akurat, representatif dan credible lewat keterkaitan hubungan dalam suatu jaringan (Nurdiani, 2014). Informan kunci di sini adalah Lurah Dangerakko selaku Ketua Pokja. Data penelitian yang digunakan peneliti merupakan data primer dan data sekunder yang diperoleh dari kegiatan wawancara, observasi dan dokumentasi. Teknik analisis data pada penelitian kualitatif dapat dilakukan bersamaan dengan proses pengumpulan data (Sugiyono, 2019). Adapun teknik analisis yang digunakan mencakup reduksi data, penyajian dan penarikan simpulan (Miles \& Huberman, 1992).

\section{HASIL DAN PEMBAHASAN}

\section{Implementasi Kampung KB Kelurahan Dangerakko}

Analisis implementasi kebijakan didasari teori implementasi kebijakan Charles 0. Jones yang didasari tiga indikator, yaitu sebagai berikut.

\section{- Organisasi}

Organisasi merupakan kegiatan pembentukan atau penataan Kembali sumber daya, unit-unit, dan metode yang menjadikan program berjalan (Jones, 1996). Pembentukan Kampung KB di Kelurahan Dangerakko diawali dengan pembentukan Panitia Pencanangan Kampung KB Kelurahan DangerakkoyangdidasariSKWali kota Palopo No. 158/II/2017. Panitia pencanangan tersebut bertugas mempersiapkan materi, sarana dan prasarana, fasilitas pelatihan dan pembinaan kelompok kegiatan di Kelurahan Dangerakko sebagai salah satu wilayah kampung KB.

Pembentukan kepengurusan Kampung KB Kelurahan Dangerakko sendiri ditetapkan kemudian berdasarkan Surat Keputusan Wali kota Palopo No. 29/I/2018 tentang Pembentukan Kelompok Kerja (Pokja) Advokasi dan Akselerasi Program Kependudukan Keluarga Berencana dan Pembangunan Keluarga (KKBPK) Tahun 2018.

Adapun panitia pelaksanaa lapangan, sebagaimana berikut.

- Pelindung/Penanggung jawab :

Mulyawati

- Penasihat : Sarifuddin Kasra

- Ketua : Muslimin

- Sekretaris : Rida Yusuf

- Bendahara : Gustiana Parusi

- Seksi Keagamaan : Hj. Hasiah Salman

- Seksi Sosial Budaya : Iskandar Damma

- Seksi Cinta \& Kasih Sayang :

Samiati

- Seksi Perlindungan : H. Ruslan

- Seksi Reproduksi : Selvi Julianti

- Seksi Pendidikan : Sudirman

- Seksi Ekonomi : Masdar Ismail

- Seksi Pelestarian Lingkungan:

Hasanuddin

Selain struktur kepengurusan tersebut, juga terdapat Penyuluh Lapangan Keluarga Berencana (PLKB/PKB) sebagai pendamping dan pengarah kegiatan. PLKB/PKB yang berkedudukan di Kelurahan Dangerakko adalah Sitti Jumiati.

Penataan struktur kepengurusan Kampung KB Kelurahan Dangerakko telah diatur secara jelas, sehingga terdapat batasan tentang wewenang, fungsi-fungsi, bagian, dan posisi. Hal tersebut ditunjukkan dengan adanya kejelasan tugas dan peran dan fungsi setiap pelaksana kegiatan, sehingga tugas pelaksana lapangan tidak terdapat overlapping yang dapat menciptakan prosedur kerja yang baku. 


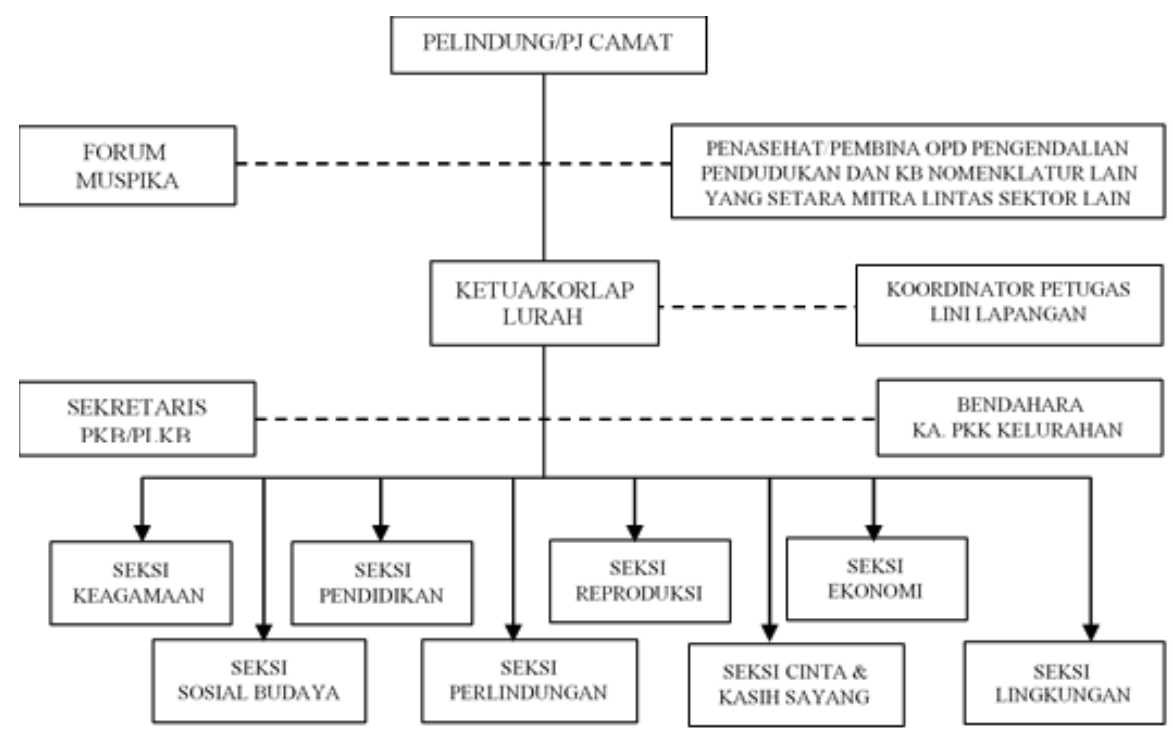

Gambar 1.

Alat Komunikasi Struktur Pengurus Kampung KB Idaman

Sumber: Data Kelurahan Dangerakko, 2019

Keberadaan mekanisme operasional mulai dari perencanaan, pelaksanaan, pemantauan hingga evaluasi dan pelaporan serta pemenuhan sumber daya manusia dalam struktur organisasi diharapkan berdampak pada efektivitas dan efisiensi pelaksanaan program Kampung KB di Kelurahan Dangerakko.

\section{- Interpretasi}

Setiap orang memiliki pemikiran dan penafsirannya masing-masing. Dalam hal kebijakan interpretasi diartikan sebagai usaha untuk memahami maksud dari pembuat kebijakan sehingga tidak ada bias dalam penafsiran dan pelaksanaan pencapaian tujuan kebijakan tersebut (Jones, 1996).

Pada implementasi program kampung KB di Kelurahan Dangerakko terdapat pedomoan pengeloaan kepada masing-masing pelaksana struktur lapangan, sebagaimana wawancara dengan Sekretaris Kampung KB Kelurahan Dangerakko, Rida Yusuf:

"BKKBN memberikan buku petunjuk sebagai panduan pelaksana tugas
Pengelola Kampung KB Kelurahan Dangerakko. Di samping itu, pengelola diberi pelatihan pengurusan Program Kampung KB oleh Panitia Kota Palopo. Selama kegiatan tersebut diberi arahan terkait tugas dan fungsi pengelola, teknis pengelolaan hingga pelaporan, serta sharing kendala yang sekiranya mungkin dihadapi dan bagaimana solusi yang diberikan. Selain itu, diberikan pelatihan dan pembinaan program kerja seperti BKR, BKL, dan terutama PIK-R"

Berdasarkan hasil penelitian terkait dengan interpretasi, maka dapat diketahui bahwa pemahaman oleh pelaksana Program Kampung KB Kelurahan Dangerakko sudah berjalan baik di mana pemahaman terkait pelaksana, penerimaan terhadap peran masing-masing, penyampaian, informasi, dan sosialisasi sudah dijalankan. Namun, sebagaimana diketahui bahwa pelatihan hanya dilakukan sebelum pembentukan pelaksana KKB, maka dapat diketahui bahwa dalam hal ini juga masih kurang optimal.

Idealnya, tahapan pelatihan dan pembinaan terkait pengelolaan tidak hanya 
diberikan pada saat awal pembentukan, namun juga harus dilaksanakan dan diperbaharui selama program masih berlangsung.

Selain pemahaman pelaksana Program Kampung KB, peneliti menggali pemahaman masyarakat sebagai sasaran kebijakan mengenai pemahaman Program Kampung KB. Ibu Dinda selaku warga Kelurahan Dangerakko yang berprofesi sebagai Ibu Rumah Tangga menyampaikan bahwa pemahamannya atas program Kampung KB adalah peningkatan kesejahteraan masyarakat. Adapun kegiatan yang telah beliau ikuti, di antaranya penyuluhan tentang $\mathrm{KB}$, cara hidup sehat pada masa pandemi, pelatihan keterampilan, serta posyandu bagi balita dan anak-anak yang diadakan setiap bulan. Melalui program ini, beliau menuturkan bahwa masyarakat terbuka menerima informasi dan kegiatan, serta aktif mendukung contohnya melalui gotong-royong pembangunan pinggiran sungai serta pembangunan sarana terkait.

Berbeda lagi dengan pemahaman Rizka Tri warga kelurahan Dangerakko yang berstatus pelajar SMA. Hasil wawancara dengan RIzka diperoleh bahwa pemahaman Rizka dan teman-temannya terkait Program KB adalah mengenai peningkatan pemakaian kontrasepsi bagi setiap keluarga. Padahal ada tujuan lebih jauh yang diharapkan dari sekadar pemakaian alat kontrasepsi, yaitu pembangunan masyarakat itu sendiri.

Hal ini menunjukkan bahwa interpretasi mesyarakat secara keseluruhan mengenai kebijakan program Kampung KB, namun berbeda antara masyarakat dewasa dan pelajar. Idealnya pelajar apa lagi di level SMA sudah memahami pentingnya program Kampung KB bukan hanya pada peningkatan penggunaan kontrasepsi tetapi juga menuju pemberdayaan dan pembangunan masyarakat itu sendiri.

\section{- Aplikasi}

Keberhasilan kebijakan tidak hanya dilihat dalam tumpukan kertas saja, namun perlu penerapan/pengaplikasian berupa penyediaan layanan secara rutin dalam mencapai tujuan dimaksud (Jones, 1996). Program Kampung KB Idaman Kelurahan Dangerakko dijabarkan dalam rencana strategis dan indikator kinerja sebagai mana tampak pada Tabel 2.

Berdasarkan data pada Tabel 2 diketahui bahwa terdapat dua puluh empat target kegiatan yang harus dilaksanakan untuk mencapai sasaran strategi terkait operasional integrasi program KKBPK (Kependudukan, Keluarga Berencana dan Pembangunan Keluarga) dan program pembangunan lainnya di Kampung KB.

Sebagaimana sasaran strategis yang ditetapkan, Program Kampung KB Kelurahan Dangerakko telah melaksanakan kegiatan selama tahun 2020 oleh masing-masing seksi, sebagai berikut.

1. Pertemuan Pokja Kampung KB Kelurahan Dangerakko Kota Palopo, (Januari 2020);

2. Musyawarah Kelurahan Kampung KB Idaman Kelurahan Dangerakko (Februari 2020);

3. Pertemuan Kemitraan Kampung KB dengan OPD terkait Kota Palopo (Maret 2020);

4. Pertemuan Lokakarya mini Kampung KB Idaman Kelurahan Dangerakko (Mei 2020);

5. Pertemuan Poktan Tribina Kelurahan Dangerakko (Agustus 2020);

6. Kegiatan Poktan Tribina Kampung KB Idaman Kelurahan Dangerakko (Agustus 2020);

7. Kegiatan Orientasi Kader Kampung KB Percontohan Kelurahan Dangerakko (Agustus 2020);

8. Kegiatan Pokja Kampung KB Kelurahan Dangerakko (Agustus 2020); 
Tabel 2. Program Anggaran Dana Bantuan Operasional Keluarga Berencana Kampung KB Idaman Kelurahan Dangerakko

\begin{tabular}{|c|c|c|c|}
\hline No. & Sasaran Strategi & Indikator Kinerja & Target \\
\hline \multirow[t]{4}{*}{1} & \multirow{4}{*}{$\begin{array}{l}\text { Operasionalisasi Integrasi } \\
\text { Program KKBPK dan } \\
\text { Program } \quad \text { Pembangunan } \\
\text { Lainnya di Kampung KB }\end{array}$} & $\begin{array}{l}\text { 1. Tersedia Operasionalisasi } \\
\text { Kelompok Kerja Kampung KB }\end{array}$ & 6 Kegiatan \\
\hline & & 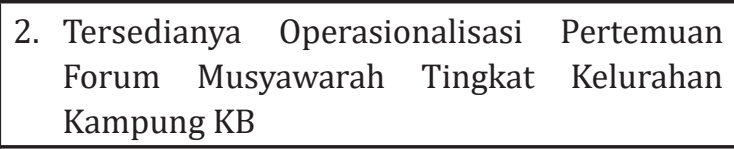 & 6 Kegiatan \\
\hline & & $\begin{array}{l}\text { 3. Tersedianya Operasionalisasi Pertemuan } \\
\text { Lokakarya Mini Tingkat Kecamatan }\end{array}$ & 6 Kegiatan \\
\hline & & $\begin{array}{l}\text { 4. Tersedianya Operasionalisasi Pertemuan } \\
\text { Ketahanan Keluarga Kelompok Kegiatan } \\
\text { (Poktan) Tribina di Kampung KB }\end{array}$ & 6 Kegiatan \\
\hline
\end{tabular}

Sumber: Data Kelurahan Dangerakko, 2020

9. Kegiatan pertemuan forum musyawarah di Kampung KB Idaman Kelurahan Dangerakko (Agustus 2020);

10. Kegiatan lokakarya mini (Lokmin) Kampung KB Kelurahan Dangerakko (Agustus 2020);

11. Kegiatan Poktan Tribina Kampung KB Idaman Kelurahan Dangerakko (Agustus 2020); dan

12. Pertemuan Pokja Kampung KB Kelurahan Dangerakko Kota Palopo (September 2020).

Berdasarkan informasi di atas diketahui bahwa dari dua puluh empat kegiatan yang direncanakan pada 2020, sudah sebagian besar program terlaksana, namun sebagian lagi masih belum terealisasi. Informasi di atas juga menunjukkan bahwa sudah terdapat dua kali pertemuan yang digunakan untuk melakukan pembahasan terkait program kerja yang sudah terlaksana dan akan direalisasikan. Hal tersebut menunjukkan bahwa dalam pelaksanaan kegiatan juga terdapat proses evaluasi yang telah dilakukan pengurus/pengelola KKB Idaman Kelurahan Dangerakko.

Program KKBPK sebagaimana disebutkan dalam situs bkkbn.go.id menyebutkan bahwa indikator keberhasilan terdiri dari:
1. Setiap keluarga mampu melaksanakan fungsi secara optimal

2. Terbinanya kesertaan ber-KB

3. Tersedianya pusat-pusat pelayanan KKBPK

4. Meningkatnya partisipasi keluarga dalam kelompok kegiatan

5. Tumbuh dan berkembangnya "gotongroyong" masyarakat dalam membangun Kampung KB.

Terkait dengan terbinanya kesertaan ber-KB, berikut disajikan data capaian akseptor KB baru per-mix kontrasepsi di Kelurahan Dangerakko Tahun 2017 dan Tahun 2019 pada Tabel 3.

Tabel 3. Data Capaian Alat Kontrasepsi Baru Per-Mic Kelurahan Dangerakko Tahun 2017-2019

\begin{tabular}{crcc}
\hline \multirow{2}{*}{ No. } & \multirow{2}{*}{$\begin{array}{c}\text { Jenis Alat } \\
\text { Kontrasepsi }\end{array}$} & \multicolumn{2}{c}{ Tahun } \\
\cline { 3 - 4 } 1 & IUD & $\mathbf{2 0 1 8}$ & $\mathbf{2 0 1 9}$ \\
2 & MOW & 5 & 6 \\
3 & MOP & 0 & 12 \\
4 & Kondom & 9 & 1 \\
5 & Implan & 5 & 8 \\
6 & Suntik & 66 & 85 \\
7 & Pil & 38 & 39 \\
\hline Jumlah & 138 & 151 \\
\hline
\end{tabular}

Sumber: Dokumentasi Kelurahan Dangerakko, 2020 
Berdasarkan data Tabel 2 diketahui capaianakseptorKBdariTahun2017keTahun 2019 mengalami peningkatan. Keikutsertaan ber-KB paling tinggi terdapat pada jenis alat kontrasepsi suntik dan pil. Dengan demikian disimpulkan bahwa indikator terbinanya keikutsertaan ber-KB, Program Kampung KB di Kelurahan Dangerakko dapat dikatakan berhasil. Partisipasi masyarakat Kelurahan Dangerakko dalam kelompok kegiatan, dapat dilihat dalam grafik Gambar 2.

Gambar 2. menunjukkan kelompok Bina Keluarga Lansia (BKL) memiliki partisipasi tertinggi, namun untuk partisipasi terendah berada pada kelompok Usaha Peningkatan Pendapatan Keluarga Sejahtera (UPPKS).

Implementasian Kampung $\mathrm{KB}$ di Kelurahan Dangerakko pada aspek aplikasi tersebut sudah baik. Hal tersebut dibuktikan dengan adanya penerimaan lingkungan masyarakat dan dukungan masyarakat untuk terlibat dalam program kerja Kampung KB, ditandai dengan peningkatan keikutsertaan ber-KB, cukup tingginya partisipasi keluarga dalam kelompok kegiatan, dan tumbuh berkembangnya gotong-royong yang dibuktikan dengan terlibatnya masyarakat misalnya dalam pembenahan jalan dan rehab gerbang kampung KB.
Selain itu, keberhasilan dalam aspek aplikasi juga sudah tersedianya sebagian pusat pelayanan KKBPK pada Oktober 2020, yaitu BKB (Bina Keluarga Berencana), BKR (Bina Keluarga Remaja), BKL (Bina Keluarga Lansia), Kelompok UPPKS (Usaha Peningkatan Pendapatan Keluarga Sejahtera), PIK-R (Pusat Informasi Konseling Remaja), dan Rumah Dataku. Namun, untuk sarana dan prasarana sekretariat KKB belum tersedia.

\section{Faktor Penunjang dan Faktor Penghambat Keberhasilan Kampung KB Kelurahan Dangerakko}

Pada pengimplementasian sebuah program, pasti terdapat faktor yang menunjang terlaksananya program, namun juga terdapat faktor penghambat dari tercapainya sasaran strategi yang ada. Pada pelaksanaan implementasi Kampung KB di Kelurahan Dangerakko juga terdapat faktor penunjang dan faktor penghambat.

Wawancara dengan Ibu Rida Yusuf selaku Sekretaris Pengurus Kampung KB menyampaikan bahwa selain memperoleh dukungan dari dinas-dinas terkait, antusiasme masyarakat untuk berpartisipasi aktif merupakan pendukung. Karena

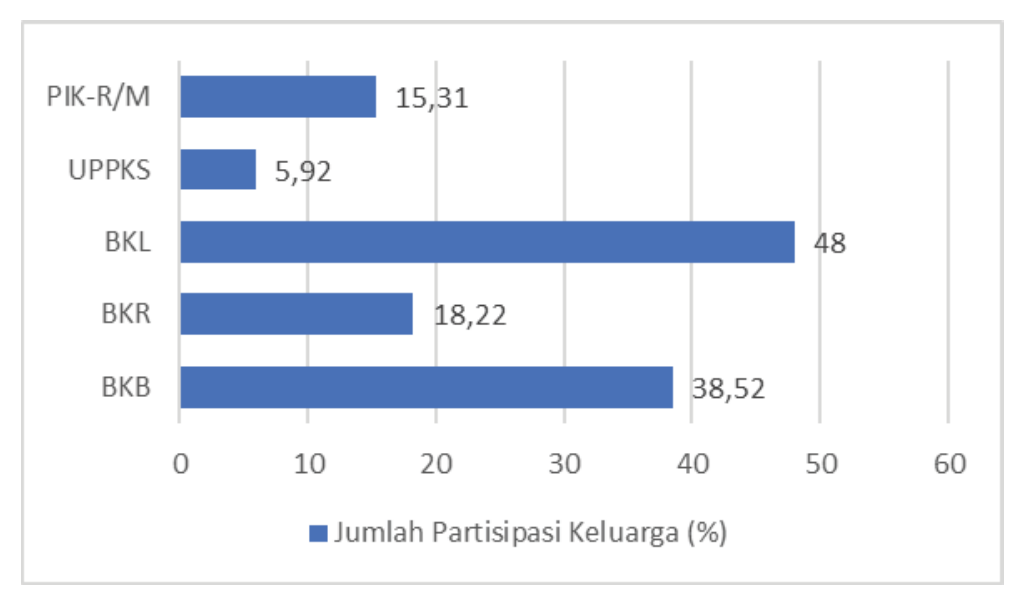

Gambar 2.

Presentasi Partisipasi Keluarga dalam Kelompok Kegiatan

Sumber: kampungkp.bkkbn.go.id/profile/8080 
bagaimanapun program ini dibuat untuk, oleh dan dari masyarakat. Sedangkan faktor penghambat berjalannya program ini adalah mindset masyarakat yang ada bahwa kontrasepsi hanya untuk wanita dan ketakutan dari para wanita sendiri bahwa dengan ber-KB akan susah memiliki anak berikutnya.

Tabel 4. Ketidaksertaan ber-KB masyarakat Kelurahan Dangerakko

\begin{tabular}{cll}
\hline No & $\begin{array}{c}\text { Alasan Ketidaksertaan } \\
\text { ber-KB }\end{array}$ & Jumlah \\
\hline 1 & Ingin Anak Segera & 76 jiwa \\
2 & Ingin Anak Kemudian & 59 jiwa \\
3 & Tidak Ingin Anak & 36 jiwa \\
4 & Hamil & 12 jiwa \\
\hline & Total & 183 jiwa \\
\hline
\end{tabular}

Sumber: Diolah peneliti, 2020

Situasi pandemi saat ini juga menjadi hambatan dalam kegiatan sosialisasi dan pelaksanaan kelompok kegiatan lainnya.

\section{Upaya Mencapai Indikator Keberha- silan Kampung KB di Kelurahan Dan- gerakko}

Dalam mencapai indikator keberhasilan Kampung KB Idaman di Kelurahan Dangerakko terdapat upaya-upaya yang dilakukan. Berikut ini disajikan upaya yang dilakukan pengelola atau pengurus Kampung KB Kelurahan Dangerakko, terdiri dari:

- Upaya dalam menarik partisipasi masyarakat untuk berkontribusi dalam tercapainya terbinanya kesertaan ber$\mathrm{KB}$, pelaksanaan fungsi keluarga secara optimal yaitu

a. Sosialisasi kepada masyarakat di Kelurahan Dangerakko terkait pemberdayaan dan perencanaan keluarga menuju keluarga kecil bahagia yang biasanya dilakukan setelah posyandu.

b. Pelatihan dan pembinaan mengenai pemanfaatan pekarangan rumah untuk area bercocok tanam. c. Penyuluhan tentang program KB yang biasanya dilakukan PLKB/ PKB Kelurahan Dangerakko, setiap selesai kegiatan posyandu.

d. Pelatihan terhadap kader BKB, BKR, BKL, Kader UPPKS, dan PIK-R, sehingga dapat melaksanakan peran dengan baik dan benar.

- Upaya dalam peningkatan partisipasi keluarga untuk membangun kampung KB secara gotong-royong serta dalam menyediakan pusat-pusat KKBPK yaitu

a. Musyawarah dan sosialisasi program kerja yang akan dilakukan kepada masyarakat kelurahan Dangerakko, sehingga masyarakat mengetahui dan dapat berpartisipasi secara aktif.

b. Melakukan koordinasi dengan OPD dan dinas terkait, misalnya dalam pembangunan talud sungai, pembuatan rumah baca, pembagian Al-Qur'an dan Iqra', ataupun dalam sosialisasi terkait kesehatan.

- Upaya yang dijabarkan tersebut sejalan dengan informasi yang diperoleh dari wawancara dengan Lurah Dangerakko, Muslimin yang juga menjabat sebagai Ketua Kepengurusan Kampung KB. Beliau menyampaikan bahwa:

"Pengurus Kampung KB senantiasa mengusahakan Kerja sama dengan dinas-dinas terkait dalam pelaksanaan program. Misalnya di tengah situasi pandemic corona-19 yang menyerang saat ini kami bekerja sama dengan Dinas Kesehatan dan Gugus Tugas untuk memberikan edukasi terhadap masyarakat. Selain itu dorongan kepada masyarakat untuk berpartisipasi aktif melalui musyawarah dan sosialisasi agar masyarakat menyadari keberhasilan program ini demi kesejahteraan Bersama, bukan hanya kepentingan pelaksana". 


\section{SIMPULAN}

Hasil yang diperoleh dari penelitian ini, ditarik beberapa simpulan, antara lain:

1. Implementasi program dinilai berjalan dengan baik didasari indikator implementasi kebijakan menurut Charles O. Jones (1996), yaitu sebagai berikut.

a. Terpenuhinya sumber daya yang dibutuhkan dalam pelaksanaan, struktur organisasi, dan pembagian peran fungsi yang jelas, serta mekanisme operasional yang baik telah menunjukkan kesesuaian aspek organisasi yang diharapkan.

b. Pelaksanaan KKB Kelurahan Dangerakko sudah berjalan cukup efektif, yang ditunjukkan dengan pemahaman pelaksana terhadap peran dan fungsi, penerimaan terhadap peran masing-masing, serta penyampaian, informasi, dan sosialisasi yang sudah dijalankan. Namun, sebagaimana diketahui bahwa pelatihan hanya dilakukan sebelum pembentukan pelaksana Kampung Keluarga Berencana (KKB), maka dapat diketahui bahwa dalam hal ini juga masih kurang optimal.

c. Aspek aplikasi dinilai tercapai dengan baik, dibuktikan dengan penerimaan dan dukungan masyarakat untuk terlibat dalam program kerja Kampung KB. Ditandai dengan peningkatan keikutsertaan ber-KB, cukup tingginya partisipasi keluarga dalam kelompok kegiatan, dan tumbuh berkembangnya gotongroyong yang dibuktikan dengan terlibatnya masyarakat misalnya dalam pembenahan jalan dan rehab gerbang kampung KB. Selain itu, juga sudah tersedianya beberapa pusat pelayanan KKBPK, yaitu BKB
(Bina Keluarga Berencana), BKR (Bina Keluarga Remaja), BKL (Bina Keluarga Lansia), Kelompok UPPKS (Usaha Peningkatan Pendapatan Keluarga Sejahtera), PIK-R (Pusat Informasi Konseling Remaja), dan Rumah Dataku, walaupun untuk sarana dan prasarana sekretariat KKB belum tersedia.

2. Faktor pendukung terlaksananya program Kampung KB di Kelurahan Dangerakko, yaitu partisipasi masyarakat yang aktif, dukungan dari dinas dan OPD, serta pembinaan dan sosialisasi pada pengurus $\mathrm{KB}$ di lapangan. Hambatan yang dialami dalam pelaksanaan, yaitu situasi dan kondisi terkait pandemi korona, serta mitos dan anggapan yang salah dari beberapa masyarakat.

3. Upaya yang dilakukan untuk mencapai keberhasilan dalam pengimplementasian, yaitu sosialisasi kepada masyarakat terkait program kerja, pelatihan dan pembinaan kader pelaksana, penyuluhan tentang program $\mathrm{KB}$ setelah posyandu oleh PKLB/PKB, dan melakukan koordinasi serta kerja sama dengan OPD/ dinas terkait program.

\section{Ucapan Terima Kasih}

- Penelitian ini dapat terlaksana dengan baik berkat bantuan dari berbagai pihak. Terkhusus penulis mengucapkan terima kasih kepada Pemerintah Kota Palopo khususnya aparat dan masyarakat Kelurahaan Dangerakko yang membantu dalam proses pengumpulan data selama kegiatan penelitian, Program Pascasarjana IPDN, serta Tim Editorial Jurnal Ilmu Administrasi Publik (JIAP) sehingga tulisan ini dapat terbit dalam bentuk jurnal.

\section{DAFTAR RUJUKAN}

Anggraeni, N., Afifudin, \& Suyeno. (2020). Im- 
plementasi Program Kampung Keluarga Berencana dalam Meningkatkan Kualitas Hidup Masyarakat (Studi Kasus Desa Sumberkarang Kabupaten Mojokerto). Jurnal Respons Publik Vol. 14, No. 1, 32-41.

Arikunto, S. (2019). Prosedur Penelitian Suatu Pendekatan Praktik. Jakarta: Rineka Cipta.

Arinta, F. (2018). Efektivitas Program Kampung KB Guna Mewujudkan Keluarga Kecil Mandiri (Studi Kasus: Kampung KB Lingkungan IX Kelurahan Harjosari II). Retrieved from FISIP Universitas Sumatera Utara: https: //repositori.usu.ac.id/bitstream/ handle/123456789/5649/140902060. pdf?sequence $=1 \&$ is Allowed=y

Badan Pusat Statistik Sulawesi Selatan. (2020, July 09).BadanPusatStatistikProvinsiSulawesi Selatan. Retrieved from https: //sulsel. bps.go.id/statictable/2020/07/09/286/ penduduk-laju - pertumbuhan penduduk-distribusi-persentasependuduk-kepadatan-penduduk-rasiojenis-kelamin-penduduk-menurutkabupaten-kota-di-provinsi-sulawesiselatan-2010--2019.html

Jayani,D.H.(2019,1216).2020,PendudukIndonesia Terbesar Keempat Dunia. Retrieved from Databoks: https: //databoks.katadata. co.id/datapublish/2019/12/16/2020penduduk-indonesia-terbesar-keempatdunia\#

Jones, C. O. (1996). Pengantar Kebijakan Publik [penerjemah] Ricky Ismawanto I. Jakarta: PT Grafindo Persada.
Margareni, Purnama, N., Djayastra, I., \& Yasa, I. (2016). Faktor-faktor yang Memengaruhi Kemiskinan di Provinsi Bali. Jurnal Piramida Vol. XII No. 1, 101-110.

Miles, B. M., \& Huberman, M. (1992). Analisis Data Kualitatif Buku Sumber tentang Metodemetode Baru. Jakarta: UIP.

Nurdiani, N. (2014). Teknik Sampling Snowball dalam Penelitian Lapangan. ComTech Vol. 5 No. 2 Desember, 1110-1118.

Remi, S. (2018). Strategi Mengelola Bonus Demografi dalam Era Disrupsi dan Globalisasi. Seminar Nasional Kesiapan SDM Indonesia di Era Disrupsi dan Globalisasi. AIPI-UNPAD.

Restyani, N., \& Yasa, I. (2019). Efektivitas Program Kampung Keluarga Berencana (KB) dan Dampaknya terhadap Kesejahteraan Keluarga Miskin di Kota Denpasar. e-Journal Ekonomi dan Bisnis Universitas Udayana 8.7, 711-740.

Sabilla, A., \& Purnaningsih, N. (2020). Partisipasi Masyarakat dalam Program Kampung Keluarga Berencana (KB). Jurnal Sains Komunikasi dan Pengembangan Masyarakat (JSKPM) Vol. 4 No. 5, 713729.

Sugiyono. (2019). Metode Penelitian Kuantitatif, Kualitatifdan R\&D. Edisi Ketiga. Bandung: Alfabeta. 
Virioner - Vol. $13 \backslash$ No. $2 \backslash$ Agustus 2021 